\title{
BMJ Open Self-perception of adaptation among homicidally bereaved individuals following a psychoeducational intervention: a UK longitudinal qualitative study
}

Filipa Alves-Costa, Catherine Hamilton-Giachritsis, Hope Christie, Sarah L Halligan

To cite: Alves-Costa F, Hamilton-Giachritsis C, Christie H, et al. Selfperception of adaptation among homicidally bereaved individuals following a psychoeducational intervention: a UK Iongitudinal qualitative study. BMJ Open 2018;8:e020443. doi:10.1136/ bmjopen-2017-020443

- Prepublication history and additional material for this paper are available online. To view these files, please visit the journal online (http://dx.doi. org/10.1136/bmjopen-2017020443).

Received 8 November 2017 Revised 1 May 2018 Accepted 15 June 2018

Check for updates

(C) Author(s) (or their employer(s)) 2018. Re-use permitted under CC BY-NC. No commercial re-use. See rights and permissions. Published by BMJ.

Department of Psychology, University of Bath, Bath, UK

Correspondence to

Filipa Alves-Costa;

f.alves-costa@bath.ac.uk

\section{ABSTRACT}

Objective Research on homicidal bereavement has focused on postloss impact and coping. Less is known about how individuals perceive their adjustment posthomicide. Adverse experiences are likely to leave individuals with an increased risk of developing severe psychological difficulties, such as depression, Posttraumatic stress (PTSD), anxiety and complicated grief. This study aimed to explore how individuals perceive their change and progression posthomicide and postpsychoeducational intervention.

Design Semistructured qualitative interviews were conducted both as part of a prospective study and retrospectively to allow for a longer follow-up period.

Setting Homicidally bereaved individuals who participated in a residential psychoeducational intervention offered by a national charity (Escaping Victimhood (EV)).

Participants Twenty-nine individuals (mainly females) took part: 14 as part of a 6-9-month follow-up (short-term trajectory group (STG) individuals-mean age 45.25) and 15 individuals (long-term trajectory group (LTG) individuals-mean age 48.50), retrospectively, 2 to 5 years postintervention.

Results Interviews were analysed using an inductive Thematic Analysis method. Three main themes and nine subthemes emerged, and applied to both groups, as follows: (1) actual changes perceived by the participants (increased understanding, improved coping strategies and positive self-change), (2) barriers to recovery (severe psychological difficulties over time, need for further support, reminders and close relationships with both victim and perpetrator), and finally perceived future progression (living day by day, hope and hopelessness). The only significant differences between the two groups related to the reported self-growth among LTG individuals and the perceived increased informal support among STG individuals by keeping in touch in other EV participants.

Conclusion This unique study provides insight into how homicidally bereaved individuals perceive their bereavement paths and helped to identify elements that appear to contribute for their adjustment. Importantly, it has highlighted that positive changes can also be an outcome.
Strengths and limitations of this study

- This qualitative 1:1 interview study explored the progression of 29 homicidally bereaved individuals longitudinally.

- Two different groups of participants were recruited (ie, 6-9 months and 2-5years following a psychoeducational intervention), in order to gain a longer perspective of the individual's progression over time to inform clinical practice and policy.

- This study has considered participants who have attended a residential psychological intervention.

- A community group of participants might highlight differences between individuals with different experiences of support (or none).

\section{INTRODUCTION}

Grief can be defined as an almost universal response to the loss of a loved one, although one that manifests in diverse ways. Approximately $45 \%-50 \%$ of individuals tend to respond resiliently and adjust to a non-violent death in the following 12 months. ${ }^{1}$ Nevertheless, the unique circumstances of a homicide namely the sudden, unexpected and violent nature of the death, protracted legal processes, as well as the dual private and public nature of the grief processes ${ }^{2}$ appears to leave individuals with an increased risk of developing severe and prolonged psychological difficulties. Family, social and professional issues may be other consequences. $^{34}$

In fact, growing recognition about the psychological difficulties posthomicide and its consequences across the life span have led to the increased demand in understanding the phenomenon. Prolonged and severe effects are often reported, such as post-traumatic stress responses, ${ }^{5-8}$ depression $^{6-9}$ and complicated grief $(\mathrm{CG}) .^{6-8}$ 
Furthermore, PTSD depression and CG were found to be the most common reported outcomes in both quantitative and qualitative research. ${ }^{10}$ However, other areas of the individuals' lives may also be impaired posthomicide, such as family and social relationships, as well as professional and economic status. ${ }^{4}$ In terms of personal change, research has demonstrated that homicidally bereaved individuals tend to report changed self-perceptions and world-perceptions. ${ }^{2411}$ Those changes might include beliefs related to safety and trust, sense of an unfair world, powerless and greater awareness regarding criminal activity and how ordinary people (such as themselves) can be affected by it.

Beyond the psychological effects, some research has been conducted on what coping strategies seem to be more effective. Mixed results were found regarding formal (eg, health agencies), informal (eg, friends, community organisations) and religious supports received postloss. Individuals reported both a strengthening of faith and feelings such as anger and self-questioning about God's power, a sense of (non-) community and/or unfairness. ${ }^{12}$ Other strategies included prayer, the use of alcohol or drugs and the avoidance of family members. ${ }^{13}{ }^{14}$ However, gender differences in support seeking were found among parents who have lost their child through violent deaths (not only homicide) ${ }^{15}$ where mothers were more likely to seek support (eg, formal, informal and religious) and fathers were more likely to use suppression strategies to cope with their experiences.

Finally, a more recent study ${ }^{16}$ has corroborated some of the evidence found previously. Individuals described positive strategies, such as seeking therapeutic support, becoming involved in advocacy work (by helping other individuals who have been through similar experiences) and less positive including distancing themselves from their grief by moving away, self-medicating and alcohol and/or drugs misuse and avoiding people or places. Another qualitative study ${ }^{2}$ described similar patterns of coping where adaption to the 'new normal' (posthomicide reality) was described as a necessity.

Despite the increasing academic interest in the field of homicidal bereavement, longitudinal evidencebased research is lacking, which is vitally needed in order to estimate how individuals progress and adjust over time. Some quantitative studies were conducted to estimate psychopathology, in particular following a psychological intervention for adult homicidally bereaved individuals ${ }^{17-20}$ and a few with children and adolescents. ${ }^{21} 22$ The current study provides a unique longitudinal perspective on adjustment in homicidally bereaved individuals. The few quantitative studies conducted preinterventions and postinterventions have captured how psychological difficulties tend to progress over time in terms of severity. By contrast, qualitative data have the potential to explore in depth the individuals' own perceptions of their progress and adjustment posthomicide and their experiences of intervention and support. Furthermore, by conducting interviews with the individuals at follow-ups allow exploring their perceptions about benefits of overall support.

Thus, this study aimed to contribute to the literature by gathering the individuals' perceptions about how they adjust posthomicide longitudinally. Furthermore, it sought to understand their perspectives on benefits derived from a psychoeducational intervention. To meet these aims, qualitative telephone interviews were conducted with homicidally bereaved individuals $6-9$ months and $2-5$ years postintervention. Specifically, this qualitative research (part of a wider mixed method project) analysed the individuals' narratives, in order to address the following research questions:

1. What changes occurred over time?

2. What was their perception of the benefits of a residential intervention?

3. How do individuals perceive their future selves/lives?

\section{METHOD}

\section{Paradigmatic and ethical underpinnings}

This study is a microstudy from a longitudinal mixed methods research project that adopts Pragmatism as philosophical model. Pragmatism appears to be a more flexible paradigm when compared with philosophies, such as (post)positivism, interpretivism or constructivism, which tend to describe the reality by purely considering quantitative or qualitative stands, respectively. ${ }^{23-26}$ On the contrary, pragmatism paradigm advocates the use of mixed methods in order to build and interpret knowledge. ${ }^{24}$ Thus, this qualitative study complements additional quantitative and qualitative data (reported elsewhere), in order to better explore the posthomicide experience as well as the individual's trajectories over time. Participants received full information about the research and provided written consent to participate. Furthermore, data were kept confidential with only the first author being aware of which participant number linked to which name. The other three authors only saw anonymised data. The research team developed a risk management plan in case individuals reported distress during the phone interview. At the end of the interview, participants were asked about how they felt and whether they needed further support related to any potential emotional responses caused by the interview questions. Furthermore, they were given information about national services they could seek help from if necessary. It was not necessary to take further action following any interview.

\section{Context}

Participants in this study attended a psychoeducational intervention offered by Escaping Victimhood (EV; a UK charity). EV's mission ${ }^{i}$ is to deliver a 4 day residential psychoeducational intervention following traumatic

\footnotetext{
More information about the EV programme can be found on their website: http://www.escapingvictimhood.com/.
} 
experiences, particularly homicidal bereavement for those affected by serious crime, including homicide.

Regarding the EV intervention, following an introductory session, the first three mornings are spent in psychoeducational group sessions. In the afternoons, individuals are invited to engage with experiential activities-therapeutic massages, art and photography sessions - the aim of which are to expose individuals to new coping strategies and to engage with positive creativity. One to one sessions are also offered with any of the EV facilitators and/or leaders (psychologists and social workers).

Considering the psychoeducational nature of the intervention, the sessions include a description of the psychological difficulties that are likely to occur following homicidal bereavement. Facilitators invite the individuals to engage in small group exercises to stimulate their awareness and ability to better identify symptoms. Symptom management and coping training sessions are included as part of the psychoeducation.

\section{Recruitment}

Two different samples were recruited in order to gain a long-term perspective of the individuals' trajectories post-EV intervention. First, 35 individuals who attended four consecutive groups were invited to take part in an interview 6 to 9 months after attending the EV intervention (short-term trajectory group-STG). Second, individuals who took part in the EV programme 2 to 5 years previously (long-term trajectory group-LTG) were invited to be interviewed as well; postal invitation letters were sent to 50 individuals by EV (a randomiser software package was used to select the participants). Those individuals who agreed to take part were then put in touch with the first author.

\section{Recruitment of a community group}

It is important to note that efforts to recruit a community sample (non-EV participants) were unsuccessful. The inclusion of a non-EV group would allow us to compare how groups of homicidally bereaved individuals with different experiences of support progress over time and would thereby provide more information about possible benefits of the targeted EV programme.

\section{Participants}

\section{Short-term trajectory group}

In total, 14 individuals took part in the retrospective interview 6 to 9 months following the $\mathrm{EV}$ intervention. Two males and 12 females with a mean age of 45.25 years old ( $\mathrm{SD}=7.35$; range 25-70). The highest educational qualifications achieved by the participants were: GCSE/OLevel/Equivalent, $(\mathrm{n}=10)$; A-Levels /Equivalent $(\mathrm{n}=3)$ and postgraduate certificates $(n=1)$. The sample comprised parents $(n=10)$, siblings $(n=2)$, daughters $(n=1)$ and partners of the victim $(n=1)$. The length of time since the homicide varied from 19 months to 18 years (mean=3.85; $\mathrm{SD}=1.47)$ at the time of interview. Participants were UK white residents. Five participants from this group also participated in an interview conducted immediately following the EV intervention. ${ }^{\mathrm{ii}}$

\section{Long-term trajectory group}

Fifteen female participants with a mean age of 48.50 years $(\mathrm{SD}=8.35$; range $37-73)$ agreed to take part in the interview 2-5years after attending the EV intervention (mean=3.58, $\mathrm{SD}=1.23$ ). Participants were parents of the deceased $(n=10)$, partners $(n=2)$, siblings $(n=2)$ and grandmothers $(n=1)$. Time since the homicidal loss (at the time of interview) ranged from 2 to 32 years (mean=8.59 years; $\mathrm{SD}=2.68$ ). No information was available for the participants' levels of education.

Finally, a minority of participants from each group had a history of receiving structured clinical interventions for psychological difficulties posthomicide, but the vast majority reported having received some kind of support (eg, GP, police, victims support services). Regarding the individual's ethnic background, the majority were white British UK residents.

\section{Semistructured interview}

A semistructured interview was developed by the authors (online supplementary appendix A). Thematically, this interview combined a set of flexible questions that focused on the individuals' perceptions of change post-EV intervention. In particular, participants were invited to reflect on (1) what changes had occurred over time, (2) their perceptions of the impact (or not) of the EV intervention and (3) how individuals perceived their future selves/ lives.

Interview questions were developed based on a cross-literature search in a variety of areas, including: interventions, emotional responses, psychopathology, coping and resilience, homicidal bereavement experiences and victimology. The $\mathrm{EV}$ team (experts working in this field of knowledge for several years), as well as seven homicidally bereaved individuals provided feedback. Interviews were conducted by the first author and phone-recorded, then transcribed by an independent agency ready for coding. Duration of the interview varied from 30 to $150 \mathrm{~min}$.

\section{Patient and public involvement}

Following a patient and public involvement process allowed individuals with personal experiences (homicidally bereaved individuals) to comment on and validate our semistructured interview and adjustments were made accordingly. This included changes to terminology and length of the interview as well as provided reassurance about the questions developed (ie, very likely to describe their experiences). The semistructured interview was piloted with four participants recruited by EV (as mentioned above). On a last note, findings from the current study (and wider project) will be disseminated

\footnotetext{
ii Six to 9 months prior the interview. The paper has been submitted to a journal for consideration.
} 
among all of the participants (ie, a brief summary report will be posted within 2 months).

\section{Data analysis}

Interviews were analysed using an inductive Thematic Analysis method and Themes were identified in the data and not forced into a pre-existing coding frame. ${ }^{27}$ Analyses were performed using the QSR NVivo11 software. The qualitative data analyses followed guidelines in the literature. ${ }^{27} 28$ In a primary phase, the first author listened to the audio recordings and read the transcripts several times before starting the coding process. Subsequently, overall codes were generated and revisited several times. In a second phase, an external coder (third author) conducted blind coding for almost $35 \%$ of the interviews $(n=10)$, in order to ensure academic rigour and reliability. Finally, two independent coders (second and fourth authors) validated the coding system, including reviewing initial themes and subthemes, and amendments were made (two themes were merged, as the content overlapped). Theoretical saturation-when new data did not lead to more/new information related to the research questions (Seale, 1999)—informed sample size, as suggested in the literature. ${ }^{27}$

\section{RESULTS}

Three main themes and nine subthemes were found, as outlined below. Participants from both groups (STG and LTG) provided similar narratives, therefore they were amalgamated. The following section offers a rich description of the thematic results found and direct quotes from the participants' interviews, in order to give them a voice. Furthermore, online supplementary appendix B includes additional quotes by theme. Figure 1 presents a visual summary of the superordinate themes and subthemes emerged.

\section{THEMES}

\section{Superordinate theme one: actual change}

The majority of participants $(n=28)$ felt that they had made positive changes over time, exemplified by the three subthemes: (1) increased understanding, (2) improved coping strategies and (3) positive self-change.

Related to the EV residential intervention, specifically, again most of the participants stated that they were very satisfied. Although initially this was a separate superordinate theme, the degree of overlap led to it be merged with theme one and the related subthemes.

\section{Increased understanding}

The majority of participants $(\mathrm{n}=25)$ reported having gained an in-depth understanding of what emotional and psychological responses might occur following an experience of homicidal bereavement. Thus, participants reported that the $\mathrm{EV}$ intervention increased their overall awareness of potential emotional responses/symptoms

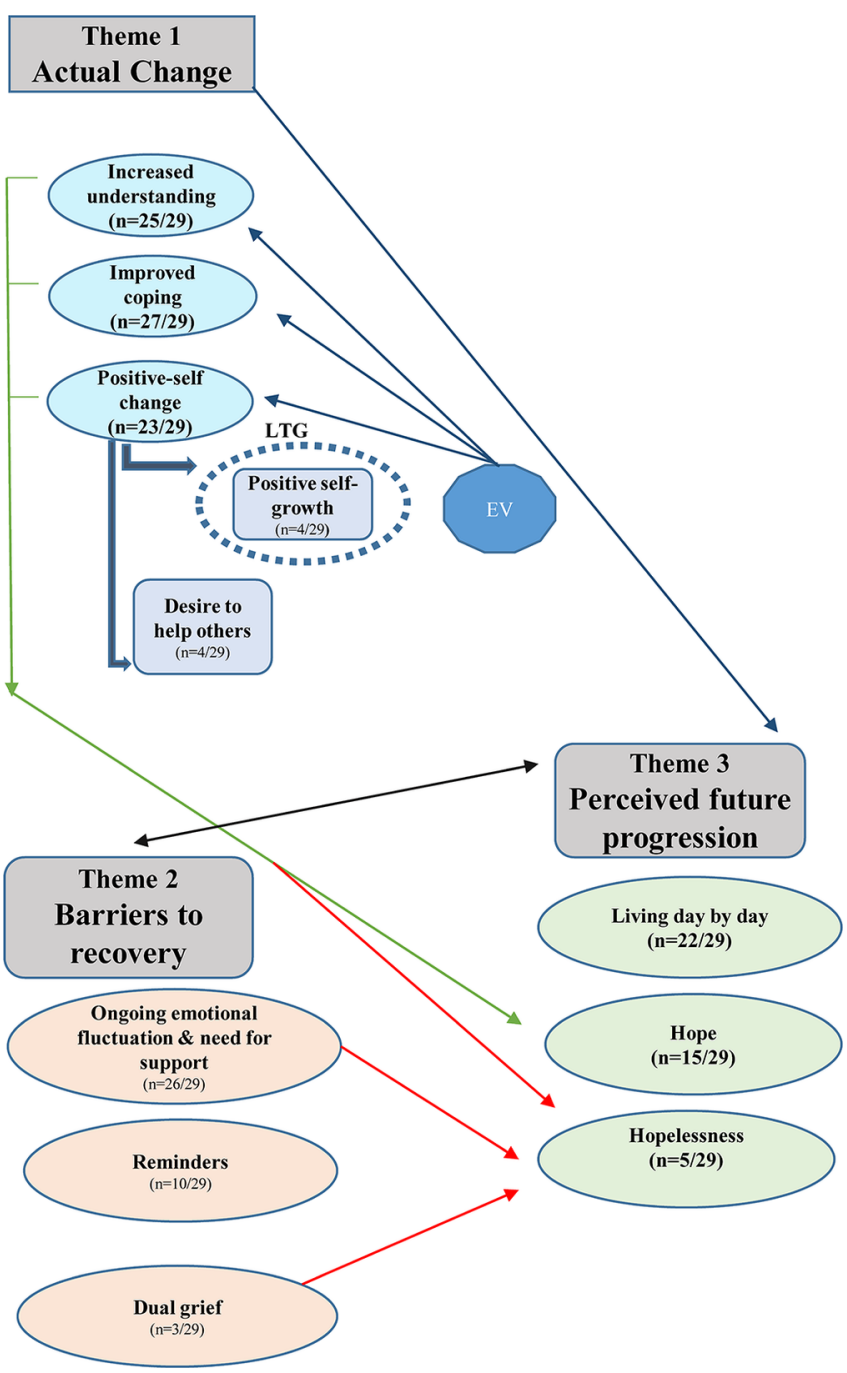

Figure 1 Thematic map with themes and subthemes. EV, Escaping Victimhood; LTG, long-term trajectory group.

posthomicide and described how this contributed to their better adjustment. 20 participants mentioned that the EV intervention gave them 'time and space' to 'put things in perspective', in order to better understand their postloss journeys. Thus, individuals' narratives demonstrated that the residential nature of the intervention was a positive aspect that allowed them to 'be away' from their day-to-day routines/contexts. In fact, this appeared to be a fundamental element that promoted self-reflection, self-care and emotional availability to better understand their responses postloss. Therefore, participant 016LTG said that:

It [EV intervention] reassured me I wasn't doing any wrong or doing anything to make things worse, and that it was all natural reactions.

Furthermore, the vast majority of the participants $(n=20)$ reflected on the fact that the $\mathrm{EV}$ intervention gave them the opportunity to realise that other individuals have been through similar experiences of being bereaved by homicide. Listening to others stories postloss (during 
social moments) contributed to an increased understanding of their own experiences as well as seeing their emotional and physiological responses normalised, as for example said by participant 030-LTG:

It [EV programme] was with likeminded people and I think it did help me progress. People that actually understood what you are going through, you realise that you are not the only one.

Further, some participants $(\mathrm{n}=5)$ noted that their family relationships improved postintervention:

I was able to, I don't know, work things out, I guess, about why my grief was different from my husband's grief and, It helped me to get the understanding that everyone reacts differently, at different times, and that was helpful. (Participant 023-STG)

On the contrary, one participant reflected on a potential negative side of meeting and sharing experiences:

I actually find now that I don't need them [homicidally bereaved individuals] because it's almost like everybody's experience is different, I don't think it helps to go over and over things with other people that have suffered. It's almost as if it becomes my, my experience of murder has been worse than yours and becomes a bit of a competition, and I just felt it was not, not beneficial at all. (Participant 033-LTG)

\section{Improved coping strategies}

Participants reflected on patterns of coping resources. The most frequent element described by participants $(n=27)$ was increased understanding about their own psychological responses postloss. In fact, individuals related their better adjustment to their greater understanding about psychological and physiological reactions that are likely to occur following a traumatic experience. It is important to note that some individuals do not spontaneously get better over time, showing that it is not just time passing. In addition, for a few individuals $(n=3)$ the $\mathrm{EV}$ intervention was perceived as too intense and academic, and for that reason not identified as a crucial element for their overall progress over time. This was the minority of individuals though.

In general, individuals provided vague narratives when describing their coping strategies. Nevertheless, the vast majority of the participants indicated that they have been better able to cope with their experiences after the EV intervention. For example, participant 024-STG said:

In general, I'm coping much better, definitely much better since [since the EV intervention].

Additionally, it was possible to identify some information about key coping strategies that individuals seemed to have mastered following the EV intervention. Several participants $(\mathrm{n}=12$; STG) reported that their communication skills improved. Thus, participants appear to have developed new strategies to better communicate/express their emotions, which improved their relationships. For example, participant 011-STG noted the importance of communication skills:

I think, if you have something on your mind or something's bothering you, you really need to communicate. You need to tell them [relatives].

Similarly, other participant mentioned that:

I found it quite hard to talk as well, eh, talk about how I'm feeling and, and communicating also with my family, it was, I found it quite difficult. But having been there [EV intervention], I sort of like came away from it and, you know, I felt myself that I could, that I could talk about what had happened and not feel, and not feel angry and not feel upset and, you know, and sort of like be, you know, be, I felt I could communicate a little bit better, especially with my wife. (Participant 014-STG)

Moreover, individuals $(n=20)$ continued using some of the coping strategies learnt at the $\mathrm{EV}$ intervention, mainly the relaxation techniques (eg, breathing exercises, $n=15$ ) as well as art and photography $(n=8)$.

I remember we were given a camera to take photographs with, and yeah I don't carry a camera around with me, but often look at things and think: Oh, I wish had a camera now. And it made me start looking at the nature and look up again. I was very down, constantly just looking at the ground. (Participant 043-LTG)

In addition, several individuals from the STG $(n=8)$ indicated that they gained informal support by keeping in touch with some of the EV participants, with that being identified as a helpful coping resource. Notably, keeping in contact was only referred by two participants in the LTG, suggesting that it is a useful strategy in the shorter term, but has less value as time goes by. As the following quote illustrates:

It's nice to be able to just get a message or a picture or a text message because you know that that other person is thinking about you and I'm thinking about them, and although you don't meet them and you don't see them because they live quite a way away, you know that that person's thinking about you and you know that they're going through the same as what you're going through. It's hard to explain because we don't really talk about it [homicide], but they are there for you. (Participant 024-STG)

\section{Positive self-change}

More than half of the participants $(n=23)$ referred to positive self-changes that impacted on their overall adjustment since their loss. The narratives of the participants reflected some 'new behaviours/attitudes' that had developed. Again, there was a strong sense that the EV intervention played an important role for the majority of them 
$(n=20)$. In fact, participants reported some examples of personal change that occurred over time in terms of emotional adaptation, psychological functioning where individuals identify their 'new normal' in a changed reality:

Now I know that I'm allowed to have good days, I'm allowed to laugh, I'm allowed to smile, I'm allowed to have a normal life, and therefore, since the programme, of course I still think about dad, of course I do, yeah, I'm allowed to be normal. I can go back to being me without feeling guilty. (Participant 12-STG)

\section{Positive self-growth}

Despite the positive self-changes reported, only a few $(\mathrm{n}=4)$ individuals from the LTG (none from the STG) reported self-growth (ie, development as an individual over and above learning positive coping styles and where they were before). For example, participant 033-LTG said that:

Everything is taken for granted. They [people, in general] should not take it for granted, because it's not. It [event] made realise that we just cannot take life for granted, love and care as much as you can.

Other quotes included:

And do you know, looking back, I think I'm a better person since [event] I'm stronger, I understand more, I value life, I value every day I live. When you lose a child, everything became so precious, every second that you spend with people that you care about, your loved ones, people close to you, treasure everything that they say and do. (Participant 032-LTG)

\section{Desire to help others}

Finally, for some individuals $(n=4)$, the positive selfchange was visible as they wanted to help others going through similar experiences, as it is illustrated in the following quote:

I would never have been able to come through this as I have done without the help that I'd had in this country, from the EV and others charities, like Victim Support. So, what I want to do now is peer support course, even though I'm going out there [leaving the UK], I can help people in an international level. (Participant 015-STG)

\section{Role of the Escaping Victimhood programme}

In summary, as noted above, participants were generally very satisfied with the EV-intervention and felt it had contributed to a better adjustment posthomicide. In fact, participants identified key EV elements that were pivotal for their overall well-being postintervention, including the group psychoeducational nature of the EV intervention, the more personalised one-to-one sessions with the facilitators as well the experiential components of the programme (ie, therapeutic massages, art and photography). Finally, the residential, warm and nurturing environment provided by EV was highly praised by the participants. Almost all of the interviewees $(n=28)$ stated that they would recommend the $\mathrm{EV}$ programme to other individuals who had experienced similar trauma.

\section{Superordinate theme two: barriers to recovery}

The second superordinate theme reflects elements participants identified as holding them back. Subthemes emerged, as follows: (1) ongoing emotional fluctuation and need for support, (2) reminders and (3) when the individuals are both close relationship to the victim and perpetrator.

\section{Ongoing emotional fluctuation and need for support}

Almost all of the participants $(n=26)$ described having felt ongoing emotional fluctuations since the event. Despite perceptions of improved well-being and mental health over time, the majority described intense and ongoing emotional responses. Consistent with that, individuals identified that ongoing support would be helpful. Further, despite acknowledging a better adjustment over time, participants highlighted the fact that such life changing experiences should require singular attention from the authority bodies. In fact, almost all of the individuals $(n=20)$ described that it would be helpful getting structured ongoing support where their ongoing needs would be followed-up over time, as said by Participant 022-STG:

It would be lovely if there was somewhere like where you could go maybe every 6 months or whatever.

Furthermore, participant 033-LTG shared that

I do really get bad days, and sometimes I feel like it would be just nice to talk to somebody. It would be nice that they would be there if needed.

Similarly, other participants stated that:

I'm okay, as you can expect, some good days, some bad days, some very bad days, and then, you know, it goes in circles. It just goes round and round, and trying to adjust to this, you know, this life without X (deceased daughter) is so very difficult. And having someone to talk to would help me, I think. (Participant 018-STG)

\section{Reminders}

Several participants $(\mathrm{n}=10)$ identified reminders that were likely to impact on their overall maladjustment, such as special dates and occasions (eg, birthdays, anniversaries, Christmas). Furthermore, social media platforms (eg, Facebook, Twitter) were also described as increasing their anxiety and emotional pain, as deactivating social media accounts of the deceased could be a prolonged processes, as described: 
Then you have special occasions where you know she (victim) is not going to be there, and this is just impossible to describe.

It is very difficult. It took us months and months until his account was completely deactivated. It was painful, very much painful. (Participant 017-STG).

\section{Close relationhip to the victim and perpetrator}

Three participants have mentioned that this duality was a factor that was holding them back, due to their close relationship with both victim and perpetrator and how that had a greater negative impact in their lives. Further, participants highlighted some particular issues that are likely to occur, namely, the emotional ambiguity felt regarding their relatives who committed the homicide. Moreover, participants reported family difficulties where changed relationships occurred or all contact ceased. Finally, individuals reflected on a perceived social stigma as well as how the criminal justice system seems not to address the particularities of such experience, as it is illustrated by the following quote:

I am the perpetrator's parent and also the victim's grandmother and it all just becomes a bit too much entwined for me to figure it out. (Participant 07-STG)

\section{Superordinate theme three: perceived future progression}

The superordinate theme relates to the participants' perceptions about their future. Subthemes emerged, as follows: (1) living day by day, (2) hope and (3) hopelessness.

\section{Living day by day}

Despite making many positive changes, overall narratives of the majority of the participants $(n=22)$ demonstrated that they continued to live day by day without forward planning. In fact, participant 018-STG said that:

I don't look far ahead anymore. It's a strange thing. I tend to live at the moment very much day-to-day and get along with, you know, go and get along with what we're doing.

\section{Hope}

Several participants $(n=15)$ were optimistic about their future. Their narratives acknowledged the chance of going through difficulties in the future, as they were living and adjusting to a changed reality. However, it also identified a perceived will to 'live again' in their 'new reality', as it is illustrated by the following quotes:

The future's good. It's not, it's not going to be easy. I mean, the past 3 years haven't been easy, but, you know, every day, every week, every month, it's getting better. You can never forget anything like this [homicide], but you have to deal with what's in front of you, you know, and I think, you know, like I say, with the support of my family and friends, you know, it can, you know, it can only get better. (Participant 014-STG)

\section{Hopelessness}

Five participants were hopeless about their future demonstrating greater distress and even two of them reported that they wish they had also died. For example, as said by participant 043-LTG:

I have survived, but sometimes I wish I hadn't. I don't mean I want to be [recognised as] a victim, but wish I had died, to be honest with you. I really wish I had died that day because, do you know what, it would have been easier to die than to suffer like this.

\section{DISCUSSION}

This study aimed to explore how individuals perceive their progression posthomicide following a residential psychoeducational intervention. As might be expected, a range of responses were found with some individuals reporting more change than others. Indeed, some described postbereavement self-growth, while a minority stated that they wished they had also died and might require further support. Thematic analyses were used to analyse the data and three main superordinate themes were found, as follows: (1) actual changes perceived by the participants (increased understanding, improved coping strategies and positive self-change), (2) barriers to recovery (ongoing emotional fluctuation and need for support, reminders and cases where the individuals are both close to the victim and perpetrator) and finally (3) perceived future progression (living by day, hope and hopelessness).

First, the main superordinate theme (actual change) and subthemes illustrate patterns of change posthomicide and following the EV intervention. Participants developing understanding of the diverse psychological difficulties that might occur postloss, and progress, seemed to be pivotal. This affected their ability to cope and often was reported to have impacted on their relationships with family members, enabling better understanding of others' experience different responses as well as making sense of their experience. ${ }^{29-31}$ This is consistent with previous research where not knowing about grief processes was considered unhelpful. ${ }^{2632}$

Regarding other coping strategies, increased informal support by keeping in touch with some of the individuals that they met at the EV intervention worked predominantly for the STG. This was less helpful for the LTG participantsfor this group, as time went by, contact with the other participants lost its value. Thus, it may be that the initial awareness of knowing you are not alone and normalisation of responses is important at the onset but loses its usefulness over time. To the best of the author's knowledge, previous studies have not looked at this, hence further studies would be useful. Continuing with the relaxation techniques (eg, breathing exercises), art and photography also appeared to be very positively received by the participants. Use of these alternative, experiential techniques is not well-addressed 
in the homicidal bereavement literature, but potentially is an area worthy of further study. Other research among victims of crime suggests that those coping strategies might be effective post-trauma, ${ }^{32}$ postsexual abuse ${ }^{33}$ as well as following domestic violence. ${ }^{34}$

Individuals also reported new behaviours/attitudes (eg, social, professional interactions, helping others). This is consistent with a recent qualitative study ${ }^{16}$ which described that individuals perceived seeking therapeutic support and becoming involved in advocacy work were both perceived as positive coping mechanisms. Hence, it may be that finding new meanings or focusing on others works well for some people. Notably, a few $(n=4 / 15)$ LTG individuals even reported personal self-growth posthomicide. In a review of the literature, Linley and Joseph ${ }^{35}$ reported that despite the adverse outcomes, positive changes can also be an outcome following traumatic events (eg, chronic illness, rape and sexual assault, military combat, maritime disasters, plane crashes, bereavement). Perhaps unsurprisingly, the majority of reviewed literature suggests that type of traumatic event does seem to impact growth as well as other elements, such as individual, social and cultural factors. ${ }^{36}$

Nevertheless, non-adaptive strategies were also reported, such as physically moving away, self-medicating and substance abuse and avoiding people or places corroborating another recent study. ${ }^{37} 38$

Second, and despite the positive changes reported, superordinate theme two summarises what the participants perceived as barriers to recovery. Thus, ongoing emotional fluctuation (eg, emotional pain, depression, exhaustion) was repeatedly highlighted. This is probably to be expected and perhaps could be an element of any programme, emphasising the normality of this. Their narratives suggested that homicidally bereaved individuals have different needs over time, due to the unpredictability of their emotional responses. Thus, individuals would possibly benefit from reassessments as the time goes by.

One area that professionals can assist with, however, is the impact of dealing with social media (including reminders about special occasions), with very practical advice about how to work with organisations to close down victims' accounts, for instance.

Another key area to consider relates to those participants who are both close to the victim and perpetrator. This group, although very small, appeared to have greater difficulties that were less responsive to the intervention. This is perhaps not surprising however highlight that this group is unique and may require specific elements of support, related to this duality. Some studies have found that intrafamilial homicides might lead to increased psychological difficulties as well as the more complexity to make sense/process their experiences. ${ }^{37-39}$ On the contrary, van Denderen et al found that perpetrator-related variables (known versus unknown to the individuals; intrafamiliar or extrafamiliar) did not impact on the individuals' levels of Post-traumatic stress (PTSD) and Complicated Grief (CG). Further longitudinal research is needed to better understand if relationship with the perpetrator impacts on individuals' psychopathology differently as the time passes by.

Superordinate theme three reflects the individuals' perceptions about their future. It was interesting to see that most retained the focus of living day by day without further planning, yet half spontaneously reported hope towards their future after the programme. Conversely, five felt hopeless and two still stated that they wished they had died. Future research should investigate this better, specifically by looking at preloss patterns and personality traits, for instance. To the best of the author's knowledge, previous studies have not focused on preloss characteristics that could potentially impact on the postloss outcomes. However, research conducted with victims of crime suggests that resilience is highly correlated with flexible personality types, ${ }^{40}$ adaptive coping resources, such as pragmatic coping ${ }^{41}$ successful past experiences of supportive and healthy relationships as well as good community resources. ${ }^{42}{ }^{43}$ Prior experience of extreme distress (PTSD) seems to predict resilience in future difficult circumstances. Therefore, and as noted by Bonanno and Mancini ${ }^{40}$ the co-occurrence of these factors will impact on the different resiliency paths of each individual and this should be included in future research.

Finally, it is important to highlight that the research team has initially explored whether group comparisons/separate themes were appropriate. Thus, it was decided to amalgamate them given the significant similar/overlapping of findings. The only significant difference between the two groups related to the reported self-growth among LTG individuals and the perceived increased informal support among STG individuals by keeping in touch with other EV participants.

\section{Clinical implications and future research}

Based on the information received from participants, interventions work well when they are group based, provide psychoeducation but also experiential activities and ongoing support. The residential nature was highlighted as very beneficial, not least because it allows participants space to be away from the dynamics within their family home and concentrate on their own style of grief, while developing understanding about others' grief responses. However, one area that could be further developed is the forward planning for when participants return home to the "cold reality'. This can include behavioural approaches, such as activity planning and goal setting, but perhaps also might include an exercise about how to match one's own grief reaction with those around them.

Generally, it can be quite difficult to identify sources of support in different geographical areas. Hence, clearly mapping services would be of benefit by showing clear paths for referral to support individuals' over time.

Future research would benefit from the inclusion of prehomicide variables, such as personal characteristics, social interactions and worldviews, as they are likely to impact on how individuals respond and progress over time following an adverse experience. Moreover, further longitudinal studies would give additional information about 
long-term progress. Finally, replication in low economic countries, where rates of homicide and overall violence tend to be greater than in Europe and USA (eg, Brazil, South Africa) are necessary, so that decisions about interventions for homicidally bereaved individuals are not based on almost exclusively European and American data. Furthermore, such research might provide information about the impact of single or multivictimisation exposure.

\section{Strengths and limitations}

This study has extended previous research on homicidal bereavement, particularly in terms of progression over time. To the best of the authors' knowledge, the research conducted up to date has mainly estimated psychopathology at different time-points, especially following psychological intervention settings. In fact, only a few quantitative longitudinal studies have estimated baseline levels of psychopathology (ie, at the beginning of psychological interventions) as well as progression usually 6-12 months after the intervention.

Overall, these previous quantitative studies demonstrated that psychological interventions are likely to contribute to the decrease of psychopathology postintervention and that the positive results are maintained at follow-ups assessments. However, these studies did not consider participants' perceptions of what was useful. Thus, the current study extends the previous research by highlighting what elements seemed to have contributed to the individual's change over time, and therefore should be considered in future interventions.

Despite the strengths, results of this study should be interpreted in the context of some limitations. First, this study only included participants who took part in the EV intervention, were predominantly females and parents of the victim. Despite the efforts to recruit a community group (non-EV participants) that was not possible. Indeed, this study would have benefited from the inclusion of a more diverse group of individuals, including those that had not attended an EV programme as well as individuals not seeking psychological support, in order to estimate potential different bereavement paths. Understanding how non-EV participants progress posthomicide in terms of psychopathology, coping and resilience trends as well as help-seeking patterns would provide more information on the particular benefits of intervention and also provide a broader perspective on adjustment following this type of loss. This could be an area to further explore in future research.

Finally, it was not possible to estimate potential systematic differences between individuals who were invited to participate but did not. Nevertheless, the quantitative data from our wider project demonstrated that there were not significant differences between those who participated and those who did not/dropped out.

\section{CONCLUSION}

This study adopted a qualitative longitudinal approach and highlighted new avenues to support homicidally bereaved individuals and help them to adjust to a 'new reality'. Despite ongoing emotional fluctuation, the current study demonstrated that positive-self change (even, occasionally, selfgrowth) is possible among this group of individuals with long-term difficulties . In contrast, some continued to report psychological difficulties. Hence, more work is required to consider how best they can be helped.

Specific elements of the interventions appear to play an important role. For that reason, psychoeducational residential interventions with experiential elements might offer a unique context for individuals to better understand psychological responses as well as acquire new tools to improve coping, positive-change, resilience and overall well-being. As noted by one participant, the programme had helped them to 'to look up again' and adjust to "their new normal'.

\section{RESEARCHER REFLEXIVITY}

Very little has been written/communicated about potential difficulties that might arise when researching traumatic topics (eg, victimisation, perpetration, war, death and dying). Furthermore, and perhaps as a direct consequence of this lack of information, very little attention has been given to doctoral students/junior researchers and how both the research process and personal characteristics might directly impact on their emotional and physical wellbeing. Those characteristics relate to the nature of the research itself, lack of clinical supervision within academia and associated absence of previous coping and management training, personal experiences of violence and trauma or other life events that can arise (before or during the course of the research). Furthermore, relatively little is known about how junior researchers (especially doctoral students who have not undertaken clinical training) respond to and make decisions in practice. .

Filipa Alves-Costa has a Degree in Psychology and a Master's Degree in Justice/Forensic Psychology. As an Assistant Psychologist and on clinical-forensic placements, she had the opportunity to get fist hand experience managing and coping with potential stressful and traumatic topics (eg, disclosure of experiences of domestic violence and abuse, sexual crimes).

During the course of this research, she adopted several strategies to insure responsible research practices, such as engaged with academic and clinical supervision, as well as found her own personal coping strategies, such as allowing herself to be in silence, exercising, stopped herself to immerse in the collected data straightway and wrote diaries/notes (not used in this research).

In fact, 'small' strategies might actually result in more responsible research practices, happier and healthier researchers/individuals and could be considered at an institutional and personal levels.

Acknowledgements The authors would like to thank all of the individuals who were willing to share their stories and to 'Escaping Victimhood', especially Barbara Tudor, Clifford Grimason and Debra Clothier for all of their support. 
Contributors FA-C led the conceptualisation and design of the project (together with the second and fourth authors). She was responsible for the project management, design of the semistructured interviews, data collection and analysis as well as the writeup of the paper. $\mathrm{CH}-\mathrm{G}$ was involved in the conceptualisation and design of the project and in the design of the semistructured interview. Finally, she contributed to discussions about themes and edited the manuscript. $\mathrm{HC}$ was involved in the blind thematic analysis of the data and provided feedback on the manuscript. SLH was involved in the conceptualisation and design of the project. She was involved in the design of the semistructured interview as well as contributed to discussions about themes and provided feedback on the manuscript.

Funding This work was supported by Escaping Victimhood and the University of Bath Graduate Studentship Allowance (collaborative scholarship).

Competing interests This $\mathrm{PhD}$ is cofunded by the national charity, Escaping Victimhood, which aims to help individuals overcome grief as a result of murder or manslaughter across the UK. However, the research team work independently to the Charity and maintain their academic and scientific rigor, following standardised ethical principles and are as objective as possible. The Charity also sees the need for the research to remain independent and able to report all outcomes, all of which (positive or negative) can help their programme develop.

Patient consent Obtained.

Ethics approval Psychology Ethics Committee at the University of Bath (Ref. 14-186)

Provenance and peer review Not commissioned; externally peer reviewed.

Data sharing statement No additional data are available.

Open access This is an open access article distributed in accordance with the Creative Commons Attribution Non Commercial (CC BY-NC 4.0) license, which permits others to distribute, remix, adapt, build upon this work non-commercially, and license their derivative works on different terms, provided the original work is properly cited, appropriate credit is given, any changes made indicated, and the use is non-commercial. See: http://creativecommons.org/licenses/by-nc/4.0/.

\section{REFERENCES}

1. Bonanno GA, Kaltman S. The varieties of grief experience. Clin Psychol Rev 2001;21:705-34.

2. Alves-Costa F, Hamilton-Giachritsis C, Halligan S. "Everything Changes": Listening to Homicidally Bereaved Individuals' Practice and Intervention Needs. J Interpers Violence 2018.

3. Miller M, Hemenway D, Azrael D. State-level homicide victimization rates in the US in relation to survey measures of household firearm ownership, 2001-2003. Soc Sci Med 2007;64:656-64.

4. Miller L. Family survivors of homicide: I. Symptoms, syndromes, and reaction patterns. Am J Fam Ther 2009;37:67-79.

5. Amick-McMullan A, Kilpatrick DG, Resnick HS. Homicide as a risk factor for PTSD among surviving family members. Behav Modif 1991;15:545-59.

6. Rheingold AA, Williams JL. Survivors of homicide: mental health outcomes, social support, and service use among a community-based sample. Violence Vict 2015;30:870-83.

7. van Denderen M, de Keijser J, Huisman M, et al. Prevalence and correlates of self-rated posttraumatic stress disorder and complicated grief in a community-based sample of homicidally bereaved individuals $\mathrm{J}$ Interpers Violence 2016;31:207-27.

8. van Denderen M, de Keijser J, Kleen M, et al. Psychopathology among homicidally bereaved individuals: a systematic review. Trauma Violence Abuse 2015;16:70-80.

9. McDevitt-Murphy ME, Neimeyer RA, Burke LA, et al. The toll of traumatic loss in African Americans bereaved by homicide. Psychological Trauma: Theory, Research, Practice, and Policy 2012;4:303-11.

10. Connolly J, Gordon R. Co-victims of homicide: a systematic review of the literature. Trauma Violence Abuse 2015;16:494-505.

11. Malone $L$. In the aftermath: listening to people bereaved by homicide. Probation Journal 2007:54:383-93.

12. Asaro MR. Working with adult homicide survivors, part I: impact and sequelae of murder. Perspect Psychiatr Care 2001;37:95-101.

13. Mezey G, Evans C, Hobdell K. Families of homicide victims: psychiatric responses and help-seeking. Psychol Psychother 2002;75:65-75.

14. Sharpe TL, Boyas J. We fall down: the African American experience of coping with the homicide of a loved one. J Black Stud 2011;42:855-73.

15. Murphy SA, Johnson LC, Weber NA. Coping strategies following a child's violent death: how parents differ in their responses. OMEGA Journal of Death and Dying 2002;45:99-118.
16. Englebrecht CM, Mason DT, Adams PJ. Responding to homicide: an exploration of the ways in which family members react to and cope with the death of a loved one. OMEGA-Journal of death and dying 2016:73:355-73.

17. Asukai N, Tsuruta N, Saito A. Pilot study on traumatic grief treatment program for Japanese women bereaved by violent death. $J$ Trauma Stress 2011;24:470-3.

18. Rheingold AA, Baddeley JL, Williams JL, et al. Restorative retelling for violent death: an investigation of treatment effectiveness, influencing factors, and durability. J Loss Trauma 2015;20:541-55.

19. Tuck I, Baliko B, Schubert CM, et al. A pilot study of a weekend retreat intervention for family survivors of homicide. West $J$ Nurs Res 2012;34:766-94.

20. Alves-Costa F, Hamilton-Giachritsis C, Pintos A, et al. Longitudinal outcomes following homicidal bereavement and psychoeducational intervention.

21. Salloum A. Group therapy for children after homicide and violence: a pilot study. Res Soc Work Pract 2008;18:198-211.

22. Salloum A, Avery L, McClain RP. Group psychotherapy for adolescent survivors of homicide victims: a pilot study. J Am Acad Child Adolesc Psychiatry 2001;40:1261-7.

23. Johnson RB, Onwuegbuzie AJ. Mixed methods research: a research paradigm whose time has come. Educational Researcher 2004;33:14-26.

24. Maxcy SJ. Pragmatic threads in mixed methods research in the social sciences: The search for multiple modes of inquiry and the end of the philosophy of formalism. In: Handbook of mixed methods in social and behavioral research: Sage, 2003:51-89.

25. Sale JE, Lohfeld LH, Brazil K. Revisiting the quantitative-qualitative debate: implications for mixed-methods research. Qual Quant 2002;36:43-53.

26. Armour MP. Experiences of covictims of homicide: Implications for research and practice. Trauma, Violence, \& Abuse 2002;3:109-24.

27. Braun V, Clarke V. Using thematic analysis in psychology. Qual Res Psychol 2006;3:77-101.

28. Braun V, Clarke V. Successful qualitative research: a practical guide for beginners: Sage, 2013

29. Armour M. Meaning making in the aftermath of homicide. Death Stud 2003;27:519-30.

30. Currier JM, Holland JM, Neimeyer RA. Sense-making, grief, and the experience of violent loss: toward a mediational model. Death Stud 2006;30:403-28.

31. Paterson A, Dunn P, Chaston K, et al. In the Aftermath. The support needs of people bereaved by homicide: a research report. London, UK: Victim Support, 2006.

32. Miranda AO, Molina B, MacVane SL. Coping with the murder of a loved one: counseling survivors of murder victims in groups. Journal for Specialists in Group Work 2003;28:48-63.

33. Emerson E. Playing for health: The process of play and self-expression in children who have experienced a sexual trauma. Doctoral dissertation, the university of Texas at Austin, order number 9225571. Ann Arbor, MI: UMI Dissertation Services, 1992.

34. Emerson E, Deborah S. Juvenile perpetrators. Mental Health Nursing 2001:22:181.

35. Linley PA, Joseph S. Positive change following trauma and adversity: a review. J Trauma Stress 2004;17:11-21.

36. Casey L. Review into the needs of families bereaved by homicide. July 2011, 2011.

37. Boelen PA, van Denderen M, de Keijser J. Prolonged grief, posttraumatic stress, anger, and revenge phenomena following homicidal loss, the role of negative cognitions and avoidance behaviors. Homicide Studies 2016;20:177-95.

38. Murphy SA, Johnson LC, Lohan J. The aftermath of the violent death of a child: an integration of the assessments of parents' mental distress and ptsd during the first 5 years of bereavement. Journal of Loss and Trauma 2002;7:203-22.

39. Harris-Hendriks J, Black D, Kaplan T. When father kills mother: guiding children through trauma and grief. 2nd edn. Florence, KY: Taylor \& Francis, 1993.

40. Bonanno GA, Mancini AD. The human capacity to thrive in the face of potential trauma. Pediatrics 2008;121:369-75.

41. Bonanno GA, Galea S, Bucciarelli A, et al. Psychological resilience after disaster: New York City in the aftermath of the September 11th terrorist attack. Psychol Sci 2006;17:181-6.

42. Luthar SS, Cicchetti D, Becker B. The construct of resilience: a critical evaluation and guidelines for future work. Child Dev 2000;71:543-62.

43. Luthar SS. Resilience in development: a synthesis of research across five decades. In: Cicchetti D, Cohen DJ, eds. Developmental psychopathology (Risk, disorder, and adaptation). . 2nd ed. Hoboken, NJ: Wiley, 2006:3. 739-95. 